\title{
STEREOCHEMISTRY - RACEMIC MODIFICATION, RESOLUTION, AND ITS IMPORTANCE WITH RECENTLY USED OPTICALLY ACTIVE DRUGS
}

\author{
CHETNA BAREGAMA* \\ Department of Medicinal and Pharmaceutical Chemistry, B. R. Nahata College of Pharmacy, Mandsaur University, Mandsaur, Madhya \\ Pradesh, India. \\ Email: chetnabaregama@gmail.com
}

Received: 13 October 2017, Revised and Accepted: 27 November 2017

\section{ABSTRACT}

Stereochemistry involves the study of the relative spatial arrangement of atoms that form the structure of molecules and their manipulation. An important branch of stereochemistry is the study of chiral molecules. Optical activity is the ability of a chiral molecule to rotate the plane of planepolarized light, measured using a polarimeter. Racemic modification and resolution, both processes are very important in stereochemistry. A mixture of equal parts of enantiomers is called a racemic modification. The process of separating a racemate into pure enantiomers is known as resolution. Recently, various optically active drugs are used for the treatment for various diseases. In these drugs, some are used as mixture of enantiomers and some used as single enantiomer. For preparation of optically active drugs, racemic modification and resolution processes are generally used. Hence, this is very important to know about various steps and types of processes used for the same. Racemic modification is advantageous where racemates have more therapeutic advantages than single isomers. Resolution is advantageous where single entiomer is used for treatment because single enantiomers have less complex and more selective pharmacodynamic profile as compared to racemic mixture so have lesser adverse drug reactions, improved therapeutic profile, less chances of drug interactions than racemic mixtures. Recently used optically active drugs are amlodipine, atenolol, cetirizine, ketamine, metoprolol, omeprazole, pantoprazole, salbutamol, propranolol, clopidogrel, rabeprazole, citalopram, ibuprofen, ketoprofen, zopiclone, etodolac, salbutamol, and nateglinide.

Keywords: Stereochemistry, Racemic modification, Resolution, Enantiomers.

(C) 2018 The Authors. Published by Innovare Academic Sciences Pvt Ltd. This is an open access article under the CC BY license (http://creativecommons. org/licenses/by/4. 0/) DOI: http://dx.doi.org/10.22159/ajpcr.2018.v11i1.23090

\section{INTRODUCTION}

Stereochemistry involves the study of the relative arrangement of atoms that type the structure of molecules and their manipulation. A crucial branch of stereochemistry is that the study of chiral molecules [1]. Stereochemistry is also known as three-dimensionality (3D) chemistry because the prefix "stereo-" means "3D" [2]. The study of stereochemistry focuses on stereoisomer and spans the complete spectrum of organic, inorganic, biological, physical, and particularly, supramolecular chemistry. Stereochemistry includes ways for decisive and describing these relationships; the result on the physiological or biological properties

\section{Isomers}

An isomer is a molecule with the same chemical formula as another molecule but with a different chemical structure. That is, isomers contain the same number of atoms of each element but have different arrangements of their atoms. Isomers do not essentially share similar properties unless they even have an identical purposeful cluster. Isomers by definition square measure the molecules of identical atomic compositions, however, with completely different bonding arrangements of atoms or orientations of their atoms in house, i.e., isomers square measures 2 or a lot of completely different substances with the same molecular formula [3-5].

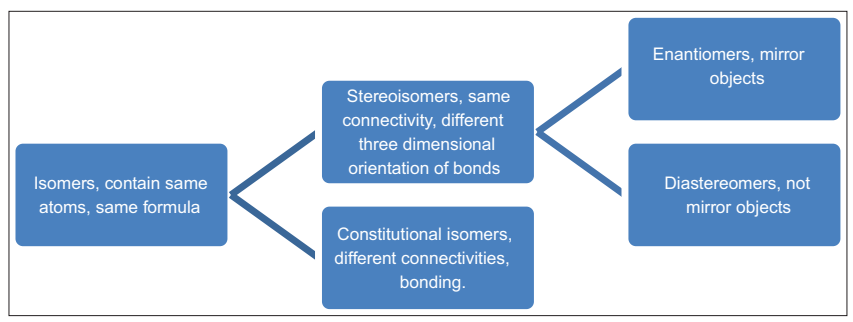

Chirality

A molecule is referred to as chiral if it is not superimposable to its mirror image means to say that a molecule is chiral is to say that its mirror image is not the same as itself [6]. The best example of chirality is our hand. Two hands cannot be superimposed identically, although our fingers of each hand are connected in the same way. The term chiral was derived from Greek word "Cheir" meaning hand and was applied as a description of left and right handedness of crystal structure, resulting from molecular asymmetry [7-9]. An atom such as carbon, nitrogen, phosphorus, sulfur, and chemical element forms a tetrahedral structure with four completely different teams hooked up to them. They type 2 non-superimposable mirror pictures. Most optical active medicine square measures chiral as a result of the presence of unsymmetrically tetrahedral carbon atoms [10,11]. A chiral molecule: It possesses 2 atoms of the same part. In theory and reality, if one were to make a plane that runs through the opposite 2 atoms, they will be able to produce what is referred to as bisecting arrange: The photographs on either aspect of the plan is that the same because of the alternative $[12,13]$.

\section{Stereoisomers}

Stereoisomers are molecules whose atomic connectivity is the same but whose three-dimensionality arrangement of atoms in space is different. Stereoisomers contain different types of isomers within itself, each with distinct characteristics that further separate each other as different chemical entities having different properties [14,15]. This has sweeping implications in biological systems. For example, most medication is usually composed of one stereoisomer of a compound, and whereas one stereoisomer might have positive effects on the body, another stereoisomer might not bind or may even be cyanogenetic. Associate example of this thalidomide can be the drug teratogen that was used throughout the 1950's to suppress sickness. The drug, unfortunately, was prescribed as a combination of stereoisomers, and whereas one stereoisomer actively worked on dominant sickness, the 
opposite stereoisomer caused serious birth defects. Ultimately, the drug was forced from the marketplace. As a result of these implications, a good deal of labor done by artificial organic chemists is in production ways to synthesize compounds that are strictly one stereoisomer. The power to visualize and manipulate molecules in three-dimensions is vitally vital so as to review and perceive the structural options that make to stereoisomerism.

\section{TYPES OF STEREOISOMERS}

- Enantiomer

- Diastereoisomer.

\section{Enantiomers}

An enantiomer is one of two stereoisomers that are mirror images of each other that are non-superposable (not identical), much as one's left and right hands are the same except for being reversed along one axis [16].

\section{Diastereoisomers}

Diastereoisomer represents another type of stereoisomer, that of a molecule that is neither mirror image nor superimposable.

\section{Pseudochirality}

Normally, once a tetrahedral atom has four totally different substituents, it is chiral. However, in rare cases, if 2 of the ligands take issue from alternative | one another by being mirror pictures of every other, the reflection of the molecule is a dead ringer for the initial, and also the molecule is achiral. This can be known as pseudochirality [14,17].

\section{Meso compound}

A molecule can have multiple stereogenic centers without being chiral overall if there is a symmetry between the two (or more) stereocenters themselves. Such a molecule is called a meso compound [10]. A meso compound or meso isomer is a non-optically active member of a set of stereoisomers, at least two of which are optically active. This means that, despite containing 2 or additional stereogenic centers, the molecule is not chiral. A meso compound is "superimposable" on its reflection, and it does not turn out a " $(+)$ " or " $(-)$ " reading once analyzed with a polariscope [17].

\section{Optical activity}

Optical activity is the ability of a chiral molecule to rotate the plane of plane-polarized light, measured using a polarimeter. A simple polarimeter consists of a light source, polarizing lens, sample tube, and analyzing lens.

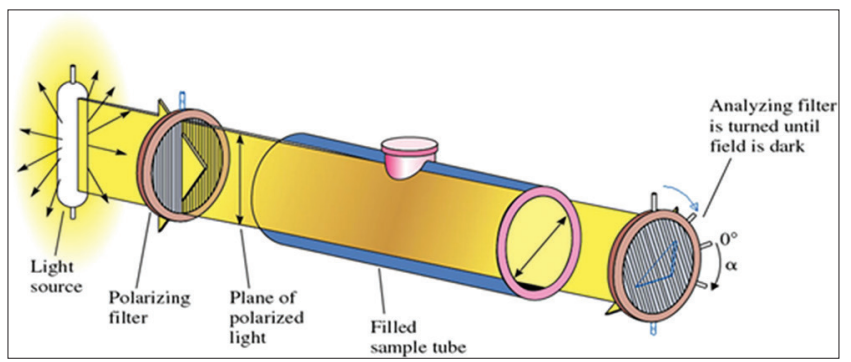

When light passes through a sample that can rotate plane-polarized light, the light appears to dim because it no longer passes straight through the polarizing filters. The amount of rotation is quantified as the number of degrees that the analyzing lens must be rotated by so that it appears as if no dimming of the light has occurred [18].

\section{Measuring optical activity}

When rotation is quantified using a polarimeter, it is known as an observed rotation because rotation is affected by path length $(\mathrm{l}$, the time the light travels through a sample) and concentration. When these effects are eliminated, WWa standard for comparison of all molecules is obtained, the specific rotation [19]. Enantiomers will rotate the plane of polarization in exactly equal amounts (same magnitude) but in opposite directions. Compounds that rotate light-weight right-handed AR aforementioned to be dextrorotatory and correspond with positive specific rotation values, whereas compounds that rotate light-weight counterclockwise AR aforementioned to be left-handed and correspond with negative values. If a compound is in a position to rotate optical phenomenon light-weight, it is aforementioned to be "optically active."

- Dextrorotary designated as d or(+), clockwise rotation (to the right)

- Levorotary designated as l or (-), anti-clockwise rotation (to the left).

\section{Specific rotation}

Specific rotation is defined as the change in orientation of monochromatic plane-polarized light, per unit distance-concentration product, as the light passes through a sample of a compound in solution. Specific rotation is an intensive property, distinguishing it from the more general phenomenon of optical rotation [20,21].

\section{Configuration}

The arrangement of atoms that characterize a particular stereoisomer is called its configuration. Stereocenters are labeled as R or S. The "right hand" and "left hand" nomenclature is used to name the enantiomers of a chiral compound. The stereocenters are labeled as $\mathrm{R}$ or S.

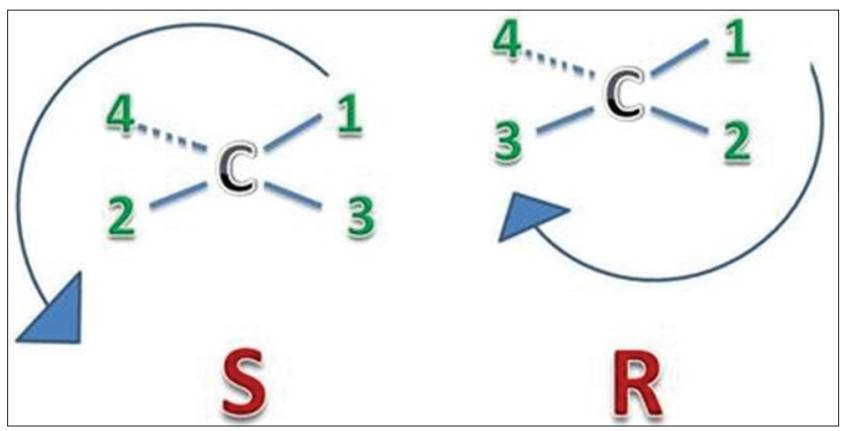

Consider the primary picture: The arrow is drawn from the best priority (1) substituent to very cheap priority (4) substituent. If the arrow points during a counterclockwise direction (left once deed the $12 \mathrm{O}^{\prime}$ clock position), the configuration at stereocenter is taken into account S ("Sinister" $\rightarrow$ Latin= "left"). If, however, the arrow points clockwise (right once deed the $12 \mathrm{O}^{\prime}$ ' clock position), then the stereocenter is labelled R ("Rectus" $\rightarrow$ Latin= "right"). The R or S is then more as a prefix, in parenthesis, to the name of the enantiomorph of interest.

\section{SEQUENCE RULES TO ASSIGN PRIORITIES TO SUBSTITUENTS}

Before applying the $\mathrm{R}$ and $\mathrm{S}$ terminology to a stereocenter, the substituents should be prioritized in line with the subsequent rules [22].

\section{Rule 1}

First, examine at the atoms directly attached to the stereocenter of the compound. A substituent with a higher atomic number takes precedence over a substituent with a lower atomic number. Hydrogen is the lowest possible priority substituent because it has the lowest atomic number.

1. When dealing with isotopes, the atom with the higher atomic mass receives higher priority.

2. When visualizing the molecule, the lowest priority substituent should always point away from the viewer (a dashed line indicates this). To understand, however, this works or appearance, imagine that a clock and a pole. Attach the pole to the rear of the clock, in order that once viewing the face of the clock the pole purposes aloof from the viewer within the same manner the bottom priority substituent ought to point away.

3. Then, draw an arrow from the highest priority atom to the $2^{\text {nd }}$ highest priority atom to the $3^{\text {rd }}$ highest priority atom. As the $4^{\text {th }}$ highest priority atom is placed in the back, the arrow should appear like it 
is going across the face of a clock. If it is going right-handed, then it is associated in nursing R-enantiomer; if it is going counterclockwise, it is associated in nursing S-enantiomer. When gazing a tangle with wedges and dashes, if the bottom priority atom is not on the dotted line inform away, the molecule should be turned. Remember that

- Wedges indicate coming toward the viewer.

- Dashes indicate pointing away from the viewer.

Rule 2

If there are 2 substituents with equal rank, then proceed on the 2 substituent chains till there is a degree of distinction. First, confirm that of the chains has the primary affiliation to Associate in Nursing atom with the very best priority (the highest atomic number). That chain has the upper priority. If the chains area unit similar, proceed down the chain till some extent of distinction.

For example: An ethyl substituent takes priority over a methyl substituent. At the connectivity of the stereocenter, both have a carbon atom, which is equal in rank. Going down the chains, a methyl has only hydrogen atoms attached to it, whereas the ethyl has another carbon atom. The carbon atom on the ethyl is the first point of difference and has a higher atomic number than hydrogen; therefore, the ethyl takes priority over the methyl.

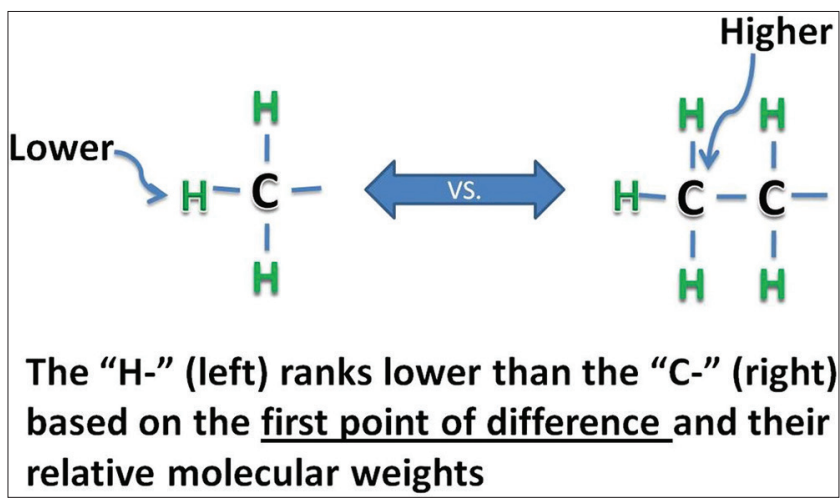

\section{Rule 3}

If a sequence is connected to identical reasonably atom double or thrice check to envision if the atom it is connected to contains a bigger number than any of the atoms that the competitive chain is connected to. purpose encompasses a larger atomic number: The chain warranted - to a similfir atom monteple times has theherger pri®trings connected to the competitory chain(s) at

-a If howesifilane among the atoms connected to the competitory chain contains a higher atomic number: That chain has the upper priority [22].

\section{Racemic modification}

A mixture of equal parts of enantiomers is called a racemic modification. A racemic modification is optically inactive: When enantiomers are mixed together, the rotation caused by a molecule of one isomer is exactly cancelled by an equal and opposite rotation caused by a molecule of its enantiomer. The prefix \pm is used to specify the racemic nature of the particular sample, as, for example, $( \pm)$-lactic acid or $( \pm)$-2-methyl-1-butanol. It is useful to compare a racemic modification with a compound whose molecules are superimposable on their mirror images, that is, with an achiral compound. They are both optically active.

\section{RACEMIC MODIFICATION}

A racemic modification or racemate is a 1:1 mixture of $(+)$ and $(-)$ enantiomers so that the overall optical rotation is zero. Racemates are denoted by the symbol $( \pm)$ or $(d, 1)$. Thus, a sample of $( \pm)$-sodium ammonium tartrate (racemic sodium ammonium tartrate), as made and studied by Louis Pasteur, contains 50\% (+) -enantiomers and 50\% (-)-enantiomers.
When a chirality center is created as a result of a chemical reaction, the product will always be formed as a racemate, in the absence of any chiral influences (such as a chiral catalyst).

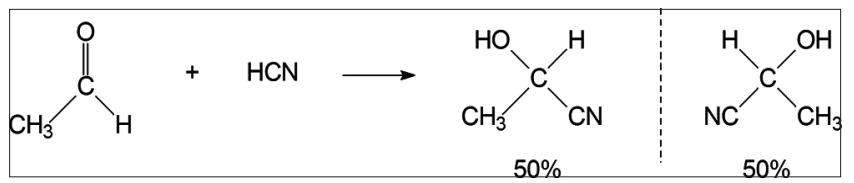

This can be a big disadvantage to the synthetic chemist whose desire will be to produce only the physiologically active form of a natural product or drug. Indeed, the other form(s) will be, at best, inactive, and at worst, toxic. Hence, the chemist has to carry reactions such as the above in the presence of some kind of chiral influence often a chiral catalyst or agent. If a chiral influence cannot be found, then the chemist must resort to resolution of the racemic product.

Resolution is the process of separating pure (+)- and (-)-enantiomers from a racemate.

Louis Pasteur was the first to resolve a racemate $( \pm)$-sodium ammonium tartrate. He was lucky in that this salt crystallized below $28^{\circ} \mathrm{C}$ as separate mirror-image crystals, one type containing only (+)-enantiomers and the other type containing only (-)-enantiomers. Thus, Pasteur was able to separate them using only magnification and tweezers. This kind of racemate is called a racemic mixture. Many other kinds of racemates (e.g., racemic compounds, whose (+)- and $(-)$-enantiomers are in the same crystal type) cannot be separated (resolved) in this way, but there are many alternative methods of resolution are available. The process by which an optically active substance is transformed into the corresponding racemic modification is known as racemization [23].

\section{FORMATION OF RACEMIC MODIFICATION}

By mixing

The most obvious and trivial way of forming a racemic modification is by intimate mixing of exactly equal amounts of dextrorotatory (+) and laevorotatory (-) isomers. This method is related to an entropy of blending, since the racemic modification represents a lot of random state of affairs than the separate enantiomers.

\section{By synthesis}

Any synthesis of dissymmetric molecules, starting from either symmetric molecule of a racemic modification and using no optically active reagent or catalysy and no asymmetric physical influence always products a racemic modification the two enantiometric type of product molecules. The two common ways of production an asymmetric carbon in mole by displacement and by addition. The method is exemplified by addition of hydrogen cyanide to acetaldehyde to give lactonitrile. Here, approach from either side of carbon is equally facile, and therefore, equal number of mole of two enantiometric forms of lactonitrile, $\mathrm{CH}_{3} \mathrm{CHOHCN}$ results.

\section{By racemization}

Racemization is the process of production of racemic modification starting with one of the pure enantiomers. Since the two enantiomer have the same free energy, the equilibrium mixture will correspond to a 50-50 composition, i.e., it will be a racemic modification. Several chemical method for reaching the racemization equilibrium may be distinguished.

- Thermal racemization

One general method of racemization an optically active material is by breaking, temporarily, one of the 4 bonds to an asymmetric carbon. If, in the subsequent reformation of the bond, the group separated exchanges place with one of the remaining groups, by dyssemtric mole is converted to its enantiomer. The racemization of $\quad$ a $\quad \alpha$-phenethyl chloride, $\mathrm{c}_{6} \mathrm{~h}_{5}$ chclch $_{3}$, on distillation at atmospheric pressure may be of this type. 
- By anion formation

A second way of bringing about the process of depicted is heterolytic cleavage in a such a way that the electron pair of the bond broken stays with the R'R"R"'C group. The group is thus converted to an anion. The group is separated without its electron, usually a proton. In other word, the process involves the temporary separation usually proton.

- By cation formation

Another way of bringing about racemization by the type of process depicted to remove temporarily the group is with the pair of electron and to level $\mathrm{R}^{\prime} \mathrm{R}^{\prime \prime} \mathrm{R}^{\prime \prime} \mathrm{C}^{+}$as a carbonium ion. Usually, this type of racemization is brought about by Lewin acid which abstracts R". Examples are the racemization of $\alpha$-phenethyl chloride by means of antimony pentachloride and 2-phenylbutane by aluminum chloride.

- By reversible formation of stable inactive intermediates The carbonium ion and carbanions involved in above-described racemization are probably two intermediates but of very short half-life. An example is the racemization of $\alpha$-phenethyl chloride on dissolution in liquid sulfur dioxide or formic acid; this has been shown to proceed by dehydrohalogenation-hydrohalogenation process.

- By Walden inversion

The racemization of 2 -iodooctane by potassium iodide in refluxing acetone involves a process known as "Walden Inversion."

\section{By chemical transformation}

It is possible to change a dissymmetric mole to its enantiomeric form without ever breaking any of the bonds leading to the asymmetric atom.

Epimerization, mutarotation, and asymmetric transformation Although epimerization, mutarotation, and asymmetric transformation do not constitute racemization, they are closely related to racemization and will be taken up in this section

- Epimerization

Epimerization is defined as change in configuration at one asymmetric atom in a compound having more than one such atom. Epimerization involves interconversion of diastereomers.

- Mutarotation and asymmetric transformation

Mutarotation is the spontaneous change, with time, in the rotation of freshly prepared solutions of certain optically active substances. Eventually, their rotation reaches an equilibrium value, generally different from zero. Mutarotation may be the result of either a spontaneous epimerization or a spontaneous structural change. In the case of $(+)$-glucose, mutarotation involves a change of configuration at the number 1 carbon due to an opening and reclosing the hemiacetal ring.

The rate of mutarotation depends on temperature, solvent, and catalyst. The mutarotation of glucose is known to be acid-base catalyzed.

\section{Resolution}

The process of separating a racemate into pure enantiomers is known as resolution. The enantiomers of the racemate must be temporarily converted into diastereomers. As the physical properties of enantiomers area unit are identical, they rarely will be separated by straightforward physical strategies, such as half crystallization or distillation. Mixtures of enantiomers area unit troublesome to separate as a result of the enantiomers has identical boiling purpose. The technique is to convert the pair of enantiomers into a pair of diastereomers and to utilize the different physical characteristics of diastereomers. Enantiomers are not readily separated by conventional means, such as recrystallization or fractional distillation, since they have the same solubilities, melting points, and boiling points. Hence, special means are needed for "resolution" of 2 enantiomers. One means that resolution is to convert the combine of enantiomers into 2 diastereomers. Diastereomers are complete compounds and have different physical properties [24].

\section{METHOD OF RESOLUTION OF RACEMIC MODIFICATION}

A method of separating a racemate into pure enantiomers. The enantiomers of the racemate should be briefly reborn into diastereomers. As a result of the physical properties of enantiomers square measure identical, they rarely are separated by straightforward physical ways, like fractional crystallization or distillation. IT's solely underneath the influence of another chiral substance that enantiomers behave otherwise, and the majority ways of resolution of enantiomers square measure primarily based on this reality [25]. The various methods of resolution are as follows.

\section{CHIRAL AMINES AS RESOLVING AGENTS. RESOLUTION OF RACEMIC ACIDS}

The most unremarkably used procedure for separating enantiomers is to convert them to a mix of diastereomers which will have totally different physical properties, freezing point, boiling purpose, solubility, and so on. For example: If you have got a racemic or d,l mixture of enantiomers of associate acid and convert this to a salt with a chiral base having the D configuration, the salt is a mixture of two diastereomers, D acid. D base and L acid. D base. These diastereomeric salts are not identical and that they are not mirror pictures. Hence, they will take issue to a point in their physical properties, and a separation by physical strategies, like crystallization, could also be attainable. If the diastereomeric salts is fully separated, the acid regenerated from every salt is either completely the D or the L enantiomer.

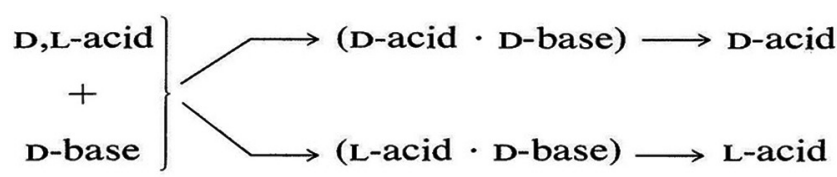

Resolution of chiral acids through the formation of diastereomeric salts needs adequate provides of appropriate chiral bases. Brucine, strychnine, and antimalarial drug of times are used for this purpose as a result of they are promptly offered, present chiral bases. Easier amines of artificial origin, such as 2-amino-1-butanol, upper, and 1-phenylethanamine, can also be used; however; initially, they have to be resolved themselves.
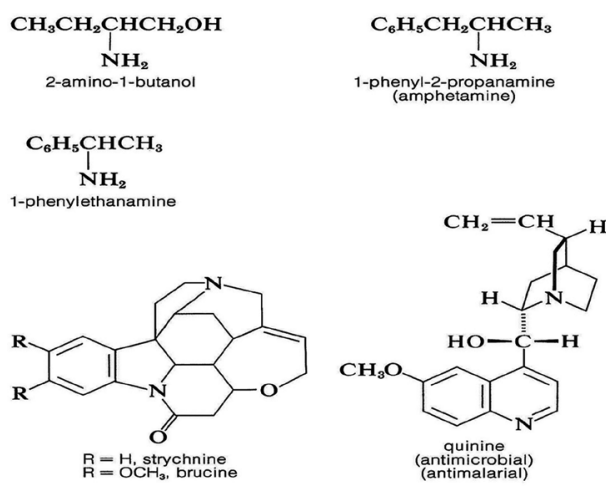

- A common reaction for chemical resolution is salt formation

\begin{tabular}{|c|c|c|c|}
\hline $\begin{array}{c}\text { RCOOH } \\
\text { (R,S)-Carboxylic } \\
\text { acid }\end{array}$ & + & $\begin{array}{l}\text { :B }= \\
\text { (R)-Base }\end{array}$ & $\begin{array}{l}\mathbf{R C O O}^{-} \mathbf{H B}^{+} \\
(\mathbf{R}, \mathbf{R})-\text { Salt }+(\mathbf{S}, \mathbf{R})-\text { Salt }\end{array}$ \\
\hline
\end{tabular}

- After separation of the diastereomers, the enantiomerically pure acids are recovered.

- Racemic acids can be resolved using commercially available chiral bases such as 1-phenylethanamine.<smiles>C[C@H](N)c1ccccc1</smiles>

(S)-1-Ph enylethan amin e

(R)-1-Phenylethan amin e 
<smiles>CCOC(=O)[C@H](C)c1ccc2cc(OC)ccc2c1</smiles>

Ethyl ester of $(S)$-nap roxen

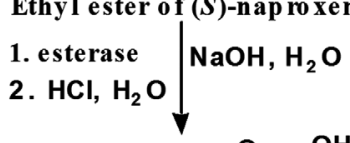<smiles>COc1ccc2cc([C@@H](C)C(=O)O)ccc2c1</smiles>

(S)-N ap roxen

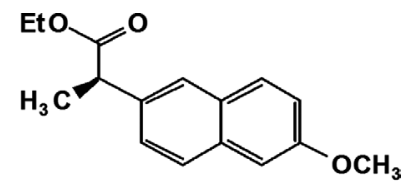

Ethyl ester of $(R)$-nap ro xen (not affected by the esterase)
Resolution of racemic base

Chiral acids, such as (+)-tartaric acid, (-)-malic acid, (-)-mandelic acid, and $(+)$-camphor-10-sulfonic acid, are used for the resolution of a racemic base.

- $\quad$ Racemic bases can be resolved using chiral acids such as:<smiles>C[C@]1([C@H](O)C(=O)O)CC[C@H](C(=O)O)[C@]1(C)C(=O)O</smiles>

(2R, 3R)-(+)-Tartaric acid (S)-(-)-Malic acid

(1S, 3R)-(+)-Camphoric aci

The principle is that the same as for the resolution of a tartaric acid with a chiral base and also the selection of acid can rely each on the convenience of separation of the diastereomeric salts, and of course, on the supply of the acid for the dimensions of the resolution concerned. Resolution ways of this type are tedious, as a result of various recrystallizations in numerous solvents could also be necessary to increasingly enrich the crystals within the less-soluble diastereomer. To work out, once the resolution is complete, the mixture of diastereomers is recrystallized till there is no any amendment within the measured optical rotation of the crystals. At this stage, it is hoped that the crystalline salt could be a pure diastereomer from that one pure compound is recovered. The optical rotation of this enantiomer will be a maximum value if it is "optically" pure because any amount of the other enantiomer could only reduce the magnitude of the measured rotation [25].

\section{Resolution of racemic alcohols}

To resolve a racemic alcohol, a chiral acid may be wont to convert the alcohol to a mix of diastereomeric esters. This can be not as usually helpfu as can be thought as a result of esters tend to be liquids unless they are terribly high-molecular weight compounds. If the diastereomeric esters are not crystalline, they need to be separated by another methodology than fragmentary crystallization. 2 chiral acids that AR helpful breakdown agents for alcohols are the foremost common methodology of breakdown Associate in Nursing alcohol is to convert it to a half-ester of a chemical group acid, like butanedioic (succinic) or one, 2-benzenedicarboxylic (phthalic) acid, with the corresponding compound. The ensuing half-ester contains a free carboxyl operate and will then be resolvable with a chiral base, sometimes brucine:

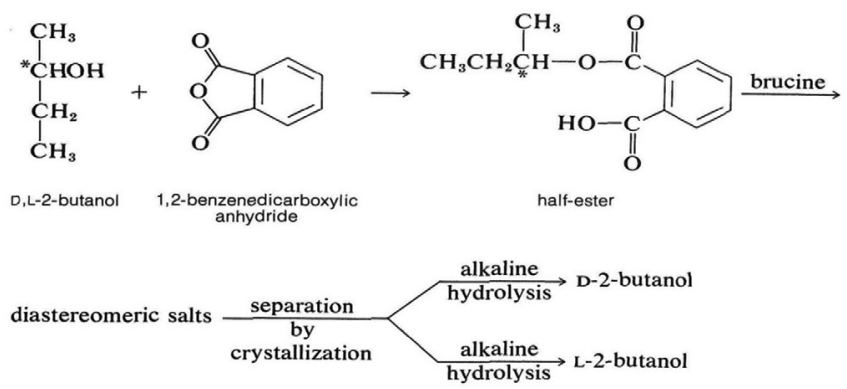

Other methods of resolution

One of the main goals within the field of chemical science is that the development of reagents with the property of "chiral recognition" such they will impact a clean separation of enantiomers in one operation while not destroying either of the enantiomers. We have not achieved that ideal, however, chromatographic methods, whereby the stationary phase is a chiral reagent that adsorbs one enantiomer more strongly than the other, have been used to resolve racemic compounds, but such resolutions seldom have led to both pure enantiomers on a preparative scale. Other methods, called kinetic resolutions, are excellent when applicable. The procedure takes advantage of variations in reaction rates of enantiomers with chiral reagents. One compound might react faster, thereby deed associate far more than the opposite compound behind. For instance, racemic hydroxy acid is resolved with the help of bound antibiotic molds that consume the clockwise compound quicker than the left-handed compound. As a result, nearly pure (-)-tartaric acid is recovered from the mixture. An obstacle of resolutions of this sort is that a lot of reactive compound, sometimes, are not redeemable from the reaction mixture [25].

\section{SOME MORE MODERN AND EASIER TYPE OF METHODS OF SEPARATION OF A RACEMIC MIXTURE INTO DEXTRO AND LAEVO COMPONENTS 1. MECHANICAL SEPARATION}

When the two forms of isomers type well outlined crystals, they will be separated by hand selecting. The crystals of $\mathrm{Na}$ ammonium ion racemate are often separated by this methodology.

\section{Biochemical separation}

In this methodology, bound small organism such as mold, bacterium, or fungi once allowed grow in an exceedingly answer of racemic mixture destroy one among the optical isomers at a way faster rate than the opposite thanks to selective assimilation. Once Penicillium glaucum is allowed to grow in an exceedingly answer of ammonia salt, it destroys the dextro chemical compound effort the leavo chemical compound.

By means of salt formation

This is a good technique for resolution. Here, the isomers of racemic mixture area unit reborn to their salts with associate in nursing optically active acid or base. The two salts obtained typically disagree in their solubilities and may be separated by the fragmentary chemical phenomenon. The salts on treatment with acid or base regenerate the optically active chemical agent.

\section{Resolution by crystallization}

$5-10 \%$ of all racemates area unit noted to crystallize as mixtures of enantiopure crystals supposed conglomerates. Louis Pasteur was the primary to conduct chiral resolution once he discovered the conception of optical activity by the manual separation of left-handed and right-handed hydroxy acid crystals in 1849. In 1882, he went on to demonstrate that by seeding a concentrated resolution of $\mathrm{Na}$ ammonium ion salt with a d-crystal on one aspect of the reactor and a l-crystal on the other aspect, crystals of opposite imbalance can type on the other sides of the reactor [26].

This type of resolution, referred to as spontaneous resolution, has additionally been incontestable with racemic methadone. In a very typical setup, $50 \mathrm{~g}$ dl-methadone is dissolved in fossil oil ether and targeted. $2 \mathrm{~mm}$-sized d- and l-crystals area unit additional and once stirring for $125 \mathrm{~h}$ at $40^{\circ} \mathrm{C} 2$ giant d-and l-crystals area unit recovered in $50 \%$ yield.

\section{RECENT OPTICALLY ACTIVE DRUGS}

There are the drugs which are used in racemization along with their isomers activity.

\section{Amlodipine}

Amlodipine, 3-ethyl 5-methyl-2-[(2-aminoethoxymethyl]-4-(2chlorophenyl)-1,4-dihydro-6-methyl-3,5-pyridinedicarboxylate, is a 
chiral calcium antagonist, currently on the market and in therapeutic use as a racemate. Amlodipine is a calcium channel blocker prescribed for the management of angina and hypertension. As a racemic mixture, amlodipine contains (R)- and (S)- amlodipine isomers, however, solely (S)- amlodipine because the active moiety possesses therapeutic activity.

S-amlodipine is related to considerably less hydrops than R-amlodipine. $\mathrm{R}$-amlopidine being a thousand-fold less active than its S-counterpart. $\mathrm{R}$-amlopidine is more rapidly eliminated from plasmathan $\mathrm{S}$-amlodipine, with mean terminal half-lives of $34.9 \mathrm{~h}(\mathrm{R})$ and $49.6 \mathrm{~h}$ (S). Thus, the attribute of the long duration of action of amlodipine is dependent on its S-enantiomer $[27,28]$. S-amlodipine is mainly responsible for blunting of precapillary postural vasoconstrictor reflex, and for other local changes, responsible for peripheral edema due to racemic amlodipine.

\section{Atenolol}

Atenolol is a drug belonging to the general class of compounds known as beta-blockers.

Beta-blockers include beta-selective (cardio-selective) adrenoreceptor blocking agents, which are exemplified by such well-known commercial products such as Tenormin.

S-atenolol is highly active enantiomer than its (R)-enantiomer possessing no activity. (S)-atenolol is the more pharmacologically effective form of atenolol. S(-)atenolol optically pure, which is free of the $\mathrm{R}(+)$ enantiomer, is a potent beta-blocking agent in the regulation of heart rate, relieving the symptoms of angina, and reduces blood pressure in individuals [29].

\section{Cetirizine}

It is a second-generation medication utilized in the treatment of pollinosis, allergies, angioedema, and hives. It is a metabolite of anxiolytic hydroxyzine and a racemic selective $\mathrm{H} 1$ receptor antagonist. Secondgeneration antihistamines like cetirizine square measure less ready to cross the barrier and so have diminished result on vascular system compared to initial generation drug [31]. The (S)-form of cetirizine possesses the affinity to alleviate/palliate allergic rhinitis. Clinical studies have indicated the equivalence of a $2.5 \mathrm{mg}$ dose of the single enantiomer compared to $5 \mathrm{mg}$ of the racemate, the S-enantiomer being essentially inactive [32]. This active compound type, (S)-, additionally possesses potent activity in treating seasonal and perennial coryza, the symptoms of allergic respiratory disease, chronic disorder nettle rash, some kinds of physical nettle rash, ANd alternative disorders as well as those who would take pleasure in an repressive action on eosinophile activity [33,34].

\section{Ketamine}

(S)-Ketamine has a greater analgesic and anaesthetic potency than the R-enantiomer. 2-3 times more potent than racemic ketamine, eliminated more rapidly as a single enantiomer than as a component of the racemate. The incidence of psychotomimetic phenomena is negligibly less with S-ketamine in comparison to racemic ketamine [35]. Most ketamine is racemic, i.e., it is composed of equal parts $\mathrm{S} / \mathrm{C}^{+}$) and $\mathrm{R} /(-)$ ketamine. The $(+)$ isomer of ketamine is more potent than the $(-)$ isomer. It also seems that $(+)$ ketamine would be superior as a psychedelic tool, for a number of reasons such as follows: (1) (+) Ketamine is generally considered to be approximately $2-3$ times more potent than (-) ketamine, (2) (+) ketamine is cleared from the body in half the time it takes for racemic ketamine. The clearance of (-) ketamine takes only slightly longer than racemic ketamine, and (3) (+) ketamine inhibits the dopamine transporter 8 times more potently than (-) ketamine.

Clinical use of $\mathrm{S}(+)$ - ketamine administered not solely related to reduction of undesirable adverse effects without altering ketamine's anesthetic and analgesic potency but also offers distinctive enhancements as a result of the reduced drug load [36].

\section{Metoprolol}

Metoprolol is a widely used cardioselective beta-blocker. However, like all other beta-blockers, it is also a racemic mixture of R- and S-isomers. The beta 1 blocking activity (cardioselectivity) of metoprolol resides in S-isomer, while R-isomer exhibits beta 2 blocking activity. As both these isomers have different pharmacological properties, racemic metoprolol can be considered a combination of two different drugs in a fixed 1:1 ratio. The needless administration of the non-betablocking R-enantiomer that makes up $50 \%$ of racemate actually puts the patient at an increased risk of side-effects, drug interactions, and loss of cardioselectivity with uptitration of dosing. Clinical experience with chirally pure S-metoprolol at half the dose of racemate has shown it to be as effective as racemate in the treatment of patients with hypertension and angina. S-metoprolol has been shown to be effective and well-tolerated in patients with coexisting diabetes, COPD, and hyperlipidemia. This confirms higher cardioselectivity of S-metoprolol in clinical settings. Less interaction potential of S-metoprolol compared to R-isomer further makes it a sensible choice in patients taking CYP2D6 inhibitors or in patients with heart failure or hepatic insufficiency [37]. Relative ventricular P-blocking potencies of the (-)-isomers of metoprolol are $>43$ times higher than those of their corresponding (+)-isomers [38].

\section{Omeprazole (OME)}

OME, a proton pump inhibitor (PPI), has been widely used as an acid inhibitory agent for the treatment of gastric acid hypersecretion disorders.

OME is a chiral compound, and the sulfinyl group is the chiral center. It is administered as a racemic (50/50) mixture of the S- and R-enantiomers. Recently, its optical S- isomer has been developed as a new drug esomeprazole which is mainly used as an active enantiomer of OME [39]. (R)- and (S)- OME show stereoselective disposition because of the enzyme-catalyzed stereoselective metabolism that leads to the higher metabolic stability of esomeprazole compared to its R-isomer and the racemate, which has been demonstrated in vitro using human liver microsomes. OME and its enantiomers ([R]- and [S]-) are metabolized in the liver by the cytochrome P450 enzyme system and the major metabolites formed are 5'-0-desmethyl OME, 5- and 3-hydroxy OME (5- and 3-OH-OME) and OME sulfone [40,41].

\section{Pantoprazole}

Pantoprazole, a selective and long-acting PPI, is a chiral sulfoxide that is used clinically as a racemic mixture of S-pantoprazole and $\mathrm{R}(+)$ pantoprazole. Animal studies have shown that S-pantoprazole is more potent (1.5-1.9 times) and effective (3-4 times) than racemate in inhibiting gastric lesions. In human patients, $20 \mathrm{mg}$ of S-pantoprazole would be at least equivalent in efficacy to $40 \mathrm{mg}$ of racemic pantoprazole [42]. The S-isomer of pantoprazole was found to be a better at inhibiting acid related lesions because of its stronger inhibition of acid secretion. It is also used in absolute risk reductions for heartburn, acid regurgitation, and bloating. The pharmacokinetics of $\mathrm{R}$ and $\mathrm{S}$ isomers of pantoprazole vary widely in extensive and poor metabolizers. The use of one compound avoids this variation and offers sure materia medica [43]

\section{Salbutamol}

Single-isomer (R)- salbutamol is not superior to a mixture of enantiomers regarding protection for bronchial hyperresponsiveness. Plasma concentrations of salbutamol are lower with R- as compared to R,S-salbutamol while equal doses of R-salbutamol taken. The use of the racemate is associated with some loss of bronchodilator potency, decreased protection against broncho-provocation, and increased sensitivity to allergen challenge and bronchoconstrictor stimuli. Repeated administrations of racemate may lead to accumulation of S-salbutamol and after cessation of bronchodilation, accomplished by R,S-salbutamol, a distinguishable amount of S-salbutamol can still be found in plasma [44]. Lower levels of R-salbutamol in plasma after treatment with pure R-salbutamol tended to be associated with higher 
bronchial reactivity.

\section{Propranolol}

The optical isomers of propranolol have been compared for their $\beta$-blocking and antiarrhythmic activities. In blocking the positive inotropic and chronotropic responses to isoprenaline, $(+)$-propranolol had less than one-hundredth the potency of (-)-propranolol. At dose levels of $(+)$-propranolol which attenuated the responses to isoprenaline, there was a significant prolongation of the PR interval of the electrocardiogram. The metabolic responses to isoprenaline in dogs (an increase in circulating glucose, lactate, and free fatty acids) were all blocked by (-)-propranolol. (+)-propranolol had no effect on fatty acid mobilization but significantly reduced the increments in both lactate and glucose. Both isomers of propranolol possessed similar depressant efficiency on isolated muscle of atria taken from guinea-pigs. Both isomers of propranolol were also capable of reversing ventricular tachycardia caused by ouabain in anesthetized cats and dogs. The dose of (-)-propranolol was significantly smaller than that of (+)-propranolol in both species but much higher than that required to produce evidence of $\beta$-blockade [45].

\section{Clopidogrel}

Clopidogrel is a potent antithrombotic drug; it demonstrated superior efficacy versus aspirin in preventing thrombotic events (myocardial infarction, stroke, and vascular death) in high-risk patients. Clopidogrel has an absolute $\mathrm{S}$ configuration at carbon 7 . The corresponding $\mathrm{R}$ enantiomer is totally devoid of antithrombotic activity, thus indicating the importance of the configuration of this asymmetric carbon for the biological activity [46-51].

\section{Rabeprazole}

Rabeprazole is accessible as a racemic mixture of 2 isomers, $\mathrm{R}$ $(+)$ isomer and $\mathrm{S}(-)$ isomer in 1:1 proportion. The chirally pure dexrabeprazole demonstrates that $\mathrm{R}(+)$ rabeprazole was more effective than $\mathrm{S}(-)$ rabeprazole and racemate rabeprazole in preventing acid-related gastric lesions [52]. The dexrabeprazole group showed a higher incidence of improvement/healing of esophagitis and relief from symptoms of regurgitation as compared to the rabeprazole group.

\section{Citalopram}

Citalopram, the $\mathrm{S}(+)$-enantiomer (whose generic name is escitalopram), is $>2$ orders of magnitude more potent than $\mathrm{R}(-)$-citalopram in vitro as an inhibitor of serotonin (5-HT) uptake. The eudismic ratio for citalopram has been calculated to be 167 . Furthermore, escitalopram has very little effect on other receptors, making it the most selective SSRI. The plasma concentration of the eutomer of citalopram (escitalopram) is usually one-third of the total citalopram concentration, with the implication being that the other two-thirds of the total citalopram concentration are drug that is mainly inactive as an antidepressant [53]. Citalopram pharmacologic activity is centered on the S enantiomer's high affinity for the serotonin transporter which is twice as high as citalopram's and 30-40 times higher than R-citalopram. This leads to an inhibition of serotonin reuptake 2 times higher for escitalopram compared with citalopram and confirms that citalopram's pharmacologic activity is due to the S-enantiomer [54].

\section{Ibuprofen}

Racemic ibuprofen, which contains equal quantities of R(-)-ibuprofen and $\mathrm{S}(+)$-ibuprofen, has been used as an anti-inflammatory and analgesic agent for over 30 years. Although the $\mathrm{S}(+)$-enantiomer is capable of inhibiting cyclooxygenase (COX) at clinically relevant concentrations, R(-)-ibuprofen is not a COX inhibitor. The two enantiomers of ibuprofen are therefore different in terms of their pharmacological properties and may be regarded as two different "drugs." They also differ in terms of their metabolic profiles. For example, R(-)-ibuprofen becomes involved in pathways of lipid metabolism and is incorporated into triglycerides along with endogenous fatty acids. $\mathrm{S}(+)$-ibuprofen does not appear to become involved in these unusual metabolic reactions [55].

\section{Ketoprofen}

Among nonsteroidal anti-inflammatory drugs (NSAIDs), 2 -arylpropionic acids exist as a racemic mixture of its enantiomeric forms, with S-enantiomers primarily responsible for inhibition of prostaglandin synthesis and inflammatory events. S-Ketoprofen efficiently inhibited carrageenan-induced edema formation, but it could also amplify the LPS-induced production of the inflammatory cytokines tumor necrosis factor and interleukin-1, in close correlation with its ability to inhibit prostaglandin synthesis. As these inflammatory cytokines are among the factors involved in carrageenan-induced inflammation and also are possibly involved in gastric damage, enhanced cytokine production could partially mask the analgesic effect of S-ketoprofen, and it can be associated with the clinical evidence of its gastric toxicity. On the other hand, R-ketoprofen contributes to the overall activity of the racemate, by playing the main role in ketoprofen-induced analgesia. Unlike the S-isomer, R-ketoprofen did not induce a significant increase of cytokine production even at COX-blocking concentrations. It is concluded that the R-isomer directly contributes to the anti-inflammatory effects of ketoprofen, being more analgesic, and because it does not amplify inflammatory cytokine production [56].

\section{Zopiclone}

Eszopiclone, a stereoisomer of zopiclone, hypnotic agent of the cyclopyrrolone family. Similar to zopiclone, eszopiclone is a synthetic compound shown to be effective in treating insomnia. The efficacy of eszopiclone has been proven in patients with insomnia associated with other comorbidities, such as a high degree of depression, generalized anxiety, rheumatoid arthritis, and sleep apnea, for which changes in sleep parameters are often observed. To date, there are no studies directly comparing the efficacy of eszopiclone and zopiclone. However, in a study of a method for assessing dissipation of the residual hypnotic effects of both drugs, a post hoc parametric analysis of reciprocal-transformed data favored eszopiclone over racemic zopiclone [57].

\section{Etodolac}

Etodolac is a commercially available NSAID containing a racemic mixture, in which the S-enantiomer has COX inhibitory activity, whereas the R-enantiomer does not [58]. Unlike all other chiral NSAIDs, the two enantiomers of etodolac are not metabolically interconvertible. Moreover, the R-enantiomer is metabolized much more slowly than the S-enantiomer, and it accumulates to 10 -fold higher concentrations than the S-enantiomer in plasma [59]. R-etodolac induced apoptosis

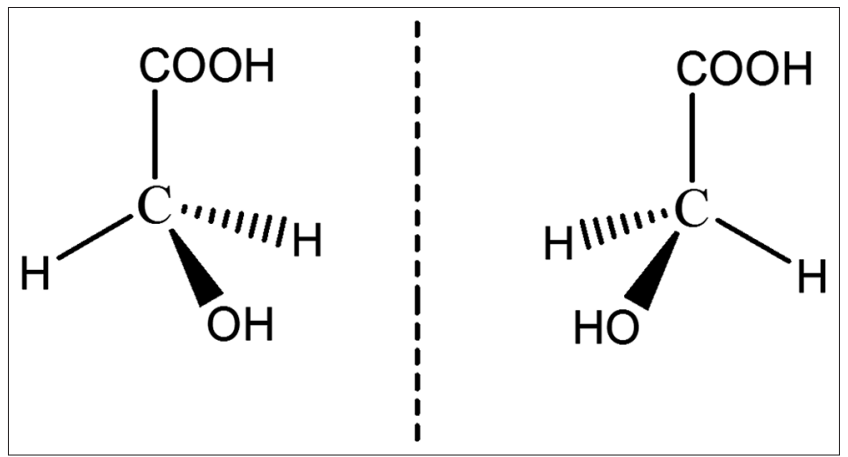

Fig. 1: Enantiomers

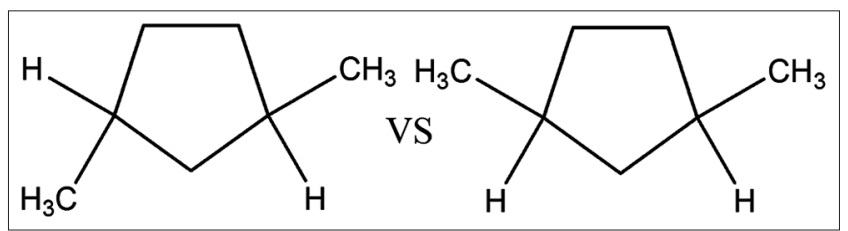

Fig. 2: Cis- versus trans- an example of diastereoisomerism 
Table 1: Harmful effects of racemic modification of optically active drugs

\begin{tabular}{|c|c|c|c|}
\hline Optically active drugs & Therapeutic group & Species & Harmful effects \\
\hline (_)-Ibuprofen & Antianalgesic & Man & Inactive \\
\hline D-DOPA & Parkinson's disease & Man & Inactive \\
\hline L-sucrose & Sweeting agent & Man & Non-metabolized \\
\hline D-ribose sugar & Sugar & Man & Less therapeutics \\
\hline L-penicillamine & Antiarthritic & Man & Toxic \\
\hline L-peptide (V13KD) & Antimicrobial & C. albicans & Trypsin proteolysis \\
\hline S-albuterol & Adrenergic & Rat & Partially active \\
\hline (b)-methadone & Analgesic & Man & Inactive \\
\hline (b)-morphine & Analgesic & Man & Inactive \\
\hline (_)-tetramisole & Anthelmintic & Man & Inactive \\
\hline S-2-[2,6-dioxopiperidine-3-yl]-phthalimidine & Sedative & Monkey & Teratogenic \\
\hline R-fenoprofen & NSAID & Rat & Inactive \\
\hline (_)-fluoxetine & Anti-depressant & Man & Inactive \\
\hline (b)-verapamil & Calcium channel blocker & Man & Inactive \\
\hline
\end{tabular}

NSAID's: Nonsteroidal anti-inflammatory drugs, C. albicans: Candida albicans

of prostate cancer but not normal epithelium. The contrasting effects might be attributable to differences in $\mathrm{RXR} \alpha$ post-translational processing in cancer and normal cells [60].

\section{Salbutamol}

Salbutamol has been wide used for the treatment of human airway diseases and has sometimes been ready because the racemic kind of the drug. However, recently, the R-enantiomer of salbutamol has been introduced into clinical practice in the treatment of asthma in humans, and this has been suggested to be an improvement on the racemic form of the drug; therefore, thus the S-enantiomer has been demonstrated to have adverse effects in the lung and thus using the R-enantiomer may improve the therapeutic ratio [61]. Studies in humans have indicated that inhalation of (R)-salbutamol (levalbuterol) produces significantly greater bronchodilatation than the equivalent dose of the racemate [62].

\section{Escitalopram}

Citalopram, a selective serotonin reuptake inhibitor, is composed of 2 enantiomers, R-citalopram and S-citalopram, 2 different non-superimposable mirror image forms of the same molecule. Separating these 2 enantiomers has enabled studying their individual properties. Citalopram's pharmacologic activity is centered on the $\mathrm{S}$ enantiomer's high affinity for the serotonin transporter which is twice as high as citalopram's and 30-40 times higher than R-citalopram. This leads to an inhibition of serotonin reuptake 2 times higher for escitalopram compared with citalopram and confirms that citalopram's pharmacologic activity is due to the S-enantiomer [63]

\section{Nateglinide}

This is used as antidiabetic drug [64]. Two enantiomers Dnateglinide and $\mathrm{L}^{-}$nateglinide are under study. Of both, Lnateglinide is more beneficial than D- nateglinide. According to pharmacodynamics studies, the L-enantiomer of nateglinide shows higher CL (tot) and VD compared with nateglinide, especially in the diabetic state [65].

\section{ADVANTAGES AND DISADVANTAGE OF RACEMIC MODIFICATION}

\section{Advantages of racemic modification}

- The use of a single isomer must be seriously taken after long clinical assessments between racemate and single enantiomer actions because in some cases, racemates have more therapeutic advantages than single isomers.

\section{Disadvantages of racemic modification}

- Side effects of "other" enantiomer could be dangerous.

- Larger or double doses of the drug will have to be taken if drug contains a mixture of enantiomers.
Example

1. Thalidomide

Optically active drug, thalidomide-which has two isomers, but only one of the optical isomers is effective (reduces morning sickness during pregnancy). The "other" enantiomer causes restriction of blood flow to developing baby limbs. Thalidomide race mises in the body, so pure drug would not work.

2. Ethambutol

Drug is optically active, used to treat tuberculosis. The other enantiomer causes blindness.

\section{HARMFUL EFFECT OF RACEMIC MODIFICATION}

\section{ADVANTAGES OF RESOLUTION OF RACEMIC MODIFICATION}

- Single enantiomers have less complex and more selective pharmacodynamic profile as compared to racemic mixture so have lesser adverse drug reactions, improved therapeutic profile, and less chances of drug interactions than racemic mixtures.

- Single enantiomers seem to be more advantageous over racemic mixtures as adverse drug reactions occurring due to one enantiomers are avoided, patients are exposed to less amount of drug, so the body is exposed to the lesser metabolic, renal, and hepatic load of drug, there is easier therapeutic drug monitoring of the active pure active enantiomers.

- Reduction in the therapeutic dose.

- Reduction in the interpatient variability in metabolism and in response to treatment.

- Simplification of the relationship between the dose and the response to treatment.

- Reduction in the toxicity and side effects due to the greater specificity of action of the isomer with the relevant biological processes.

- $\quad$ Cuts cost.

- Reduces patients dosage by half as pure is more potent.

Example

1. Levorotary isomer of all $\beta$-blockers is more potent in blocking $\beta$-adrenoceptors than their dextrorotary-isomer, such as $S(-)$ propranolol is 100 times more active than its $\mathrm{R}(+)$-antipode.

2. All ACE inhibitors such as captopril, benazepril, enalapril, and imidapril are chiral compounds under diastereoisomeric form, and most of them are marketed as single isomer. Valsartan, an angiotensin II receptor antagonist, is used as a single S-enantiomer and the activity of the R-enantiomer is clearly lower than the S-enantiomer.

\section{CONCLUSION}

Research in the field of stereochemistry has opened the new challenges and the new field avenues in the field of clinical pharmacology. Currently, a large number of clinical trials are going on to compare the efficacy 
and safety of single enantiomers and the racemic mixture. Many single enantiomer drugs will hopefully flood the market in the near future.

The impact of chirality on almost any pharmacological or biological process is well recognized and has strong repercussions in many fields of economic interest, such as the development of drugs. Besides the ethical or environmental reasons for developing single enantiomers, they may have a real therapeutic benefit, and in some cases, their development has been used as a strategy for extending patent life. In this context, a large number of methods for the preparation of optically pure compounds have been studied and widely reported. On an industrial scale, resolution is still favored over asymmetric synthesis, in particular at the early stages of development of bioactive compounds, where time constraints are a major issue. Further advances in the area of preparation will obviously favor environmentally benign protocols for technical processes, and the reduction in waste streams and recycling of solvents and materials will be very important.

\section{REFERENCES}

1. March J. Advanced Organic Chemistry. Reactions, Mechanisms, and Structure. $3^{\text {rd }}$ ed. New York: Wiley; 1985.

2. Singh K, Shakya P, Kumar AS, Kamal MA, Singh SP. Stereochemistry and its role in drug design. Int J Pharm Sci Res 2014;5:4644-59.

3. Murray R, Bender D, Botham KM, Kennelly PJ, Rodwell V, Weil PA, et al, editors. Harper's Illustrated Biochemistry. 29 ${ }^{\text {th }}$ ed. New York: Lange Medical Books, McGraw Hill Medical Publishing Division; 2012 .

4. Riley TN, De Ruiter J, Ravis WR, Clark RC. Isomerism. In: Swarbrick J, editor. Encyclopedia of Pharmaceutical Technology. $3^{\text {rd }}$ ed. London: Informa Healthcare; 2006. p. 6

5. Katzung BG, Masters SB, Trever AJ, editors. Basic and Clinical Pharmacology. $11^{\text {th }}$ ed. Noida, UP, India: Tata McGraw Hill; 2009.

6. Janice MH. The Physical Chemistry of Chirality. New York, NY: An American Chemical Society Publication; 2001.

7. Collins AN, Sheldrake GN, Crosby J. Chirality in Industry. New York: Wiley; 1992.

8. Collins AN, Sheldrake GN, Crosby J. Chirality in Industry II. New York: Wiley; 1997.

9. McConathy J, Owens MJ. Stereochemistry in drug action. Prim Care Companion J Clin Psychiatry 2003;5:70-3

10. De Ruiter J. Isomerism and Stereochemistry. Princ Drug Action I Winter 2005;1:1-11.

11. Davies NM, Wei X. Importance of chirality in drug therapy and pharmacy practice: Implication of psychiatry. Adv Pharm 2003;1:242-52.

12. Eliel E, Wilen SH, Mander LN. Stereochemistry of Organic Compounds. New York: Wiley; 1994. p. 305-7.

13. Moss GP. Basic terminology of stereochemistry. Pure Appl Chem 1996;68:2205.

14. Wainer IW. Drug Stereochemistry: Analytical Methods and Pharmacology. $2^{\text {nd }}$ ed. New York: Marcel Dekker; 1993.

15. Morrison RT, Boyd RN. Stereochemistry. Organic Chemistry. $6^{\text {th }}$ ed. Cambridge, New York: University Press; 1992. p. 1170-1

16. Cahn RS, Ingold CK, Prelog V. Specification of Molecular Chirality. Angew Chem Int Ed Eng 1966;5:385.

17. Swaran SV. Prochirality and pseudosymmetry-Some definitions. Proc Indian Natl Sci Acad 1983;49:202-12.

18. Anslyn EV, Dennis AD. Modern Physical Organic Chemistry. Chicago IL: University Science; 2005, p. 1083

19. Anslyn EV, Dennis AD. Modern Physical Organic Chemistry. Chicago IL: University Science; 2005. p. 1083.

20. Arthur IV. Vogel's Textbook of Practical Organic Chemistry. $5^{\text {th }}$ ed. Harlow: Longman; 1996.

21. McMurry J, Simanek E. Fundamentals of Organic Chemistry. $6^{\text {th }}$ ed. : Brooks Cole; 2006.

22. Schore A, Vollhardt C. Organic Chemistry Structure and Function. New York: W.H. Freeman and Company; 2007.

23. Mason JP, Hutt AJ. Stereochemical aspect of drug metabolism. In: Aboul-Enein HY, Wainer IW, editors. The Impact of Stereochemistry on Drug Development and Use. New York: Wiley; 1997. p. 45-123.

24. Eliel E, Wilen SH, Mander LN. Stereochemistry of Organic Compounds. New York: Wiley; 1994. p. 305-7.

25. Williams FT. Resolution by the method of racemic modification: A demonstration of analogy. J Chem Educ 1962;39:211

26. Porter WH. Resolution of chiral drugs. Pure Appl Chem
1991;63:1119-22.

27. Leese P, Maier G, Eszopiclone VL. Pharmacokinetic and pharmacodynamic effects of a novel sedative hypnotic after daytime administration in healthy subjects. Sleep 2002;25:45.

28. Basu D. Comparative study to evaluate the effect of S-Amlodipine versus Amlodipine on office and ambulatory blood pressure in mild to moderate hypertensives. Indian Med Gaz 2007;12:493-7.

29. Belpaire FM, Rosseel MT, Vermeulen AM, De Smet F, Bogaert MG. Stereoselective pharmacokinetics of atenolol in the rat: Influence of aging and of renal failure. Mech Ageing Dev 1993;67:201-10.

30. Ivani G, Borgi B, Van Oven H. Levobupivacaine. Minerva Anestesiol 2001;67:20-3

31. Devalia JL, De Vos C, Hanotte F, Baltes E. A randomized, double-blind, crossover comparison among cetirizine, and ucb28557 on histamineinduced cutaneous responses in healthy adult volunteers. Allergy 2008;56:50-7.

32. Wang DY, Hanotte F, De Vos C, Clement P. Effect of cetirizine, levocetirizine and dextrocetirizine on histamine induce nasal response in healthy adult volunteers. Allergy 2001;56:339-43.

33. Tillement JP, Testa B, Brée F. Compared pharmacological characteristics in humans of racemic cetirizine and levocetirizine, two histamine H1receptor antagonists. Biochem Pharmacol 2003;66:1123-6.

34. Gillard M, Van Der Perren C, Moguilevsky N, Massingham R, Chatelain P. Binding characteristics of cetirizine and levocetirizine to human H(1) histamine receptors: Contribution of lys(191) and thr(194). Mol Pharmacol 2002;61:391-9.

35. Ihmsen H, Geisslinger G, Schüttler J. Stereoselective pharmacokinetics of ketamine: $\mathrm{R}(-)$-ketamine inhibits the elimination of $\mathrm{S}(+)$-ketamine. Clin Pharmacol Ther 2001;70:431-8.

36. Zeilhofer HU, Swandulla D, Geisslinger G, Brune K. Differential effects of ketamine enantiomers on NMDA receptor currents in cultured neurons. Eur J Pharmacol 1992;213:155-8.

37. Dasbiswas A, Shinde S, Dasbiswas D. S-metoprolol: The 2008 clinical review. J Indian Med Assoc 2008;106:259-62.

38. Boucher M, Duchêne-Marullaz P, Moundanga JL. Studies on the stereoisomers of beta-adrenoceptor antagonists in conscious A-V blocked dogs. Br J Pharmacol 1986;89:119-27.

39. Tanaka M, Ohkubo T, Otani K, Suzuki A, Kaneko S, Sugawara K, et al. Stereoselective pharmacokinetics of pantoprazole, a proton pump inhibitor, in extensive and poor metabolizers of S-mephenytoin. Clin Pharmacol Ther 2001;69:108-13.

40. Baker DE. Esomeprazole magnesium (Nexium). Rev Gastroenterol Disord 2001;1:32-41

41. Cao H, Wang M, Jia J, Wang Q, Cheng M. Comparison of the effects of Pantoprazole enantiomers on gastric mucosal lesions and gastric epithelial cells in rats. J Health Sci 2004;50:1-8

42. Kim M, Shen DD, Eddy AC, Nelson WL, Roskos LK. Inhibition of the enantioselective oxidative metabolism of metoprolol by verapamil in human liver microsomes. Drug Metab Dispos 1993;21:309-17.

43. Tybring G, Böttiger Y, Widén J, Bertilsson L. Enantioselective hydroxylation of omeprazole catalyzed by CYP2C19 in swedish white subjects. Clin Pharmacol Ther 1997;62:129-37.

44. Miura M, Satoh S, Tada H, Habuchi T, Suzuki T. Stereoselective metabolism of rabeprazole-thioether to rabeprazole by human liver microsomes. Eur J Clin Pharmacol 2006;62:113-7.

45. Evans AM. Comparative pharmacology of $\mathrm{S}(+)$-ibuprofen and (RS)ibuprofen. Clin Rheumatol 2001;20 Suppl 1:S9-14.

46. Savi P, Combalbert J, Gaich C, Rouchon MC, Maffrand JP, Berger Y, et al. The antiaggregating activity of clopidogrel is due to a metabolic activation by the hepatic cytochrome P450-1A. Thromb Haemost 1994;72:313-7.

47. Savi P, Herbert JM, Pflieger AM, Dol F, Delebassee D, Combalbert J, et al. Importance of hepatic metabolism in the antiaggregating activity of the thienopyridine clopidogrel. Biochem Pharmacol 1992;44:527-32.

48. Savi P, Labouret C, Delesque N, Guette F, Lupker J, Herbert JM, et al. P2y(12), a new platelet ADP receptor, target of clopidogrel. Biochem Biophys Res Commun 2001;283:379-83

49. Savi P, Laplace MC, Maffrand JP, Herbert JM. Binding of [3H]-2methylthio ADP to rat platelets - Effect of clopidogrel and ticlopidine. J Pharmacol Exp Ther 1994;269:772-7.

50. Savi P, Pereillo JM, Uzabiaga MF, Combalbert J, Picard C, Maffrand JP, et al. Identification and biological activity of the active metabolite of clopidogrel. Thromb Haemost 2000;84:891-6.

51. Sugidachi A, Asai $\mathrm{F}$, Ogawa $\mathrm{T}$, Inoue $\mathrm{T}$, Koike $\mathrm{H}$. The in vivo pharmacological profile of CS-747, a novel antiplatelet agent with platelet ADP receptor antagonist properties. Br J Pharmacol 2000;129:1439-46. 
52. Kim M, Yu SK, Truong QK, Mai XL, Chung HK, Kang JS, et al. Determination of rabeprazole enantiomers in commercial tablets using immobilized cellulose-based stationary phase. Arch Pharm Res 2017:40:373-81.

53. Burke WJ, Kratochvil CJ. Stereoisomers in psychiatry: The case of escitalopram. Prim Care Companion J Clin Psychiatry 2002;4:20-4

54. Jacquot C, David DJ, Gardier AM, Sánchez C. Escitalopram and citalopram: The unexpected role of the R-enantiomer. Encephale 2007;33:179-87.

55. Indra KR. Chirality in Drug Design and Development. New York: Marcel Dekkar; 2004.

56. Ghezzi P, Melillo G, Meazza C, Sacco S, Pellegrini L, Asti C. Differential contribution of $\mathrm{R}$ and $\mathrm{S}$ isomers in ketoprofen antiinflammatory activity: Role of cytokine modulation. J Pharmacol Exp Ther1 998;287:969-74

57. Pinto Jr. LR, Bittencourt LR, Treptow EC, Braga LR, Tufik S. Eszopiclone versus zopiclone in the treatment of insomnia. Clinics (Sao Paulo) 2016;71:5-9.

58. Demerson CA, Humber LG, Abraham NA, Schilling G, Martel RR, Pace-Asciak C, et al. Resolution of etodolac and antiinflammatory and prostaglandin synthetase inhibiting properties of the enantiomers. J Med Chem 1983;26:1778-80.
59. Brocks DR, Jamali F. Etodolac clinical pharmacokinetics. Clin Pharmacokinet 1994;26:259-74.

60. Matsushima-Nishiwaki R, Shidoji Y, Nishiwaki S, Yamada T, Moriwaki $\mathrm{H}$, Muto Y, et al. Aberrant metabolism of retinoid X receptor proteins in human hepatocellular carcinoma. Mol Cell Endocrinol 1996;121:179-90.

61. Matera MG, Calzetta L, Rogliani P, Bardaro F, Page CP, Cazzola M, et al. Evaluation of the effects of the R-and S-enantiomers of salbutamol on equine isolated bronchi. Pulm Pharmacol Ther 2011;24:221-6.

62. Miura M, Satoh S, Tada H, Habuchi T, Suzuki T. Stereoselective metabolism of rabeprazole-thioether to rabeprazole by human liver microsomes. Eur J Clin Pharmacol 2006;62:113-7.

63. Jacquot C, David DJ, Gardier AM, Sánchez C. Escitalopram and citalopram: The unexpected role of the R-enantiomer. Encephale 2007;33:179-87.

64. Baregama C, Kumari A. A Review on Herbal Antidiabetic Drugs Conference Publication in Book of National Symposium on Drug Development Through Natural Products. Vol. 1. Ch. 6. Baddi, HP: Maharaja Agrasen University; 2017. p. 11.

65. Tamura M, Shiba S, Kudo N, Kawashima Y. Pharmacokinetics of nateglinide enantiomers and their metabolites in goto-kakizaki rats, a model for Type 2 diabetes mellitus. Chirality 2010;22:92-8. 